ppi $201502 Z U 4645$

Esta publicación científica en formato digital es continuidad de la revista impresa ISSN-Versión Impresa 0798-1406 / ISSN-Versión on line 2542-3185Depósito legal pp $197402 Z$ U34

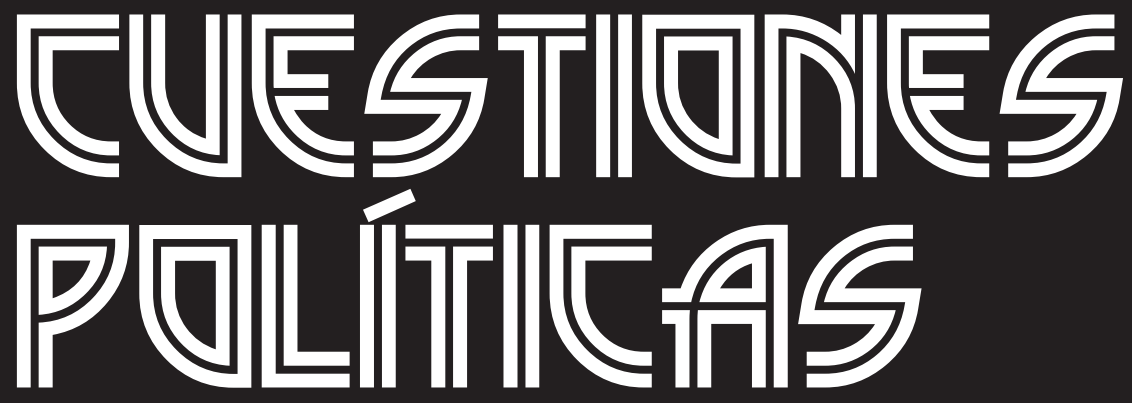

Instituto de Estudios Políticos y Derecho Público "Dr. Humberto J. La Roche" de la Facultad de Ciencias Jurídicas y Políticas de la Universidad del Zulia Maracaibo, Venezuela
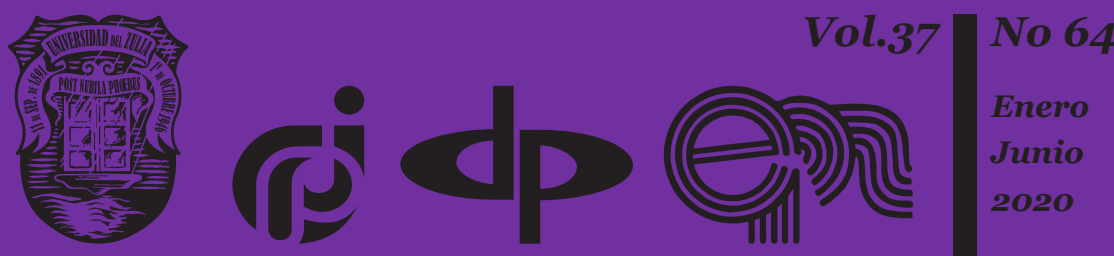


\title{
Características y evolución del liderazgo político opositor venezolano en el periodo 1999-2015
}

\author{
Gustavo Adolfo Soto Vásquez * \\ Zoribeth Carolina Lugo Vera ** \\ Jenileth Dairene Nava Medina ${ }^{* * *}$
}

\section{Resumen}

El liderazgo político forma parte de los fenómenos trascendentales estudiados desde la perspectiva del comportamiento político, toda vez que los mismos son importantes para el desarrollo y la conducción de un país en la teoría y en la realidad, Venezuela no es la excepción, tal como lo muestran diferentes hechos sociales y políticos que se abordan en el artículo. La investigación se planteó el objetivo de explicar el nacimiento de liderazgos dentro del sector opositor a través de los enfoques de liderazgo situacional, conductual y de los rasgos personales en el periodo 1999 al 2015. En lo metodológico se utilizó la hermenéutica junto a la técnica de entrevistas, a través de la selección de informantes claves que muestran características que los clasifican como líderes de rasgos personales, al tiempo que evidencian las pocas similitudes en sus visiones de país y sus líneas discursivas, además de sus claras diferencias ideológica. Se concluye que a pesar del hecho de todos los líderes presentan características de liderazgos situacionales, de rasgos personales y conductuales específicos y diferenciados, sin embargo, se encontraron en cada uno de ellos más atributos coincidentes con el estilo del liderazgo de los rasgos personales.

Palabras clave: liderazgo político en Venezuela; oposición democrática; evolución el liderazgo; características del líder; enfoques de liderazgo.

* El presente trabajo es un avance de la investigación del proyecto: "Características y evolución del liderazgo político opositor en Venezuela” desarrollado en su momento en el marco del doctorado en ciencia política de la Universidad del Zulia.

** Personal docente y de investigación en la escuela de ciencia política de la universidad del Zulia en Maracaibo-Venezuela. Email: gustafaso@hotmail.com.

*** Egresada del pregrado de la escuela de ciencia política de la Universidad del Zulia. Email: zoribethlugo.1275@gmail.com.

**** Egresada del pregrado de la escuela de ciencia política de la Universidad del Zulia. Email: jeninavam8@ gmail.com. 


\title{
Characteristics and evolution of political leadership oppositor venezuelan in the period 1999-2015
}

\begin{abstract}
Political leadership is part of the transcendental phenomena studied from the perspective of political behavior, since they are important for the development and management of a country in theory and in reality, Venezuela is not the exception, as They show different social and political facts that are addressed in the article. The research set out the objective of explaining the birth of leaderships within the opposition sector through the approaches of situational, behavioral and personal traits leadership in the period from 1999 to 2015. Methodologically, hermeneutics was used together with the technique of interviews, through the selection of key informants that show characteristics that classify them as leaders of personal traits, while showing the few similarities in their visions of country and their lines of discourse, in addition to their clear ideological differences. It is concluded that despite the fact that all leaders present specific and differentiated characteristics of situational leadership, personal and behavioral traits, however, more attributes were found in each of them that coincide with the leadership style of personal traits.
\end{abstract}

Keywords: political leadership in Venezuela; democratic opposition; leadership evolution; leader characteristics; leadership approaches.

\section{Introducción}

La Ciencia Política, tiene como fin el conocimiento de la realidad mediante la observación y la descripción ordenada y sistemática de los hechos y factores sociales y políticos, buscando su transformación hacia una situación mejor y más justa. Además, genera capacidades para intervenir, interpretar, explicar y criticar las estructuras, procedimientos, comportamientos y procesos políticos en la realidad social y política, aportándole propuestas prácticas y creativas, destinadas a mejorar su entorno y a procurar la efectividad de las respuestas gubernamentales, institucionales y públicas en general, para la satisfacción de las demandas sociales. Una de las áreas más importantes para esta ciencia social, es el comportamiento político, que tiene como fin dar explicaciones, descripciones y análisis de los actores colectivos, tales como los partidos políticos, los movimientos sociales o los grupos de interés, o de actores individuales, como los votantes o los 
Gustavo Adolfo Soto Vásquez, Zoribeth Carolina Lugo Vera y Jenileth Dairene Nava Medina 164

líderes políticos, estudiando los factores biológicos, psicológicos, sociales y ambientales que influyen en él; también se entiende por comportamiento político, todo lo que a partir de una relación o impacto genera un orden social, entendido también que todo comportamiento interpersonal o intergrupal supone algún grado de intervención de poder.

El liderazgo político es todo un proceso en el cual algunos individuos intentan o logran ejercer su influencia sobre otros. Y, a su vez, estos liderazgos pueden ser categorizados o denominados según las tipologías del mismo. Los liderazgos a nivel histórico han jugado un papel muy importante para el rumbo político de Venezuela, desde Caudillos, Militares y Demócratas hasta los líderes más Mesiánicos, sin embargo, desde esta investigación se pretende hacer un estudio sobre el contrapeso histórico, el sector opositor de uno de los periodos más interesantes es nuestra historia republicana, donde se pretende dar una explicación sobre cómo han evolucionado y cuáles son las características de los mismos.

La siguiente investigación, aborda el área del comportamiento político a través de las características y evolución del liderazgo político opositor venezolano en el período 1999- 2015. Igualmente, se intenta dar una explicación sobre el problema, que busca revelar cómo ha sido históricamente el proceso de liderazgo político de Venezuela. El liderazgo político ha sido uno de la los fenómenos más estudiados en el campo de las Ciencias Sociales, especialmente en los dominios de la psicología social y la ciencia política, pero uno de los fenómenos menos comprendidos, aunque en sus inicios los estudiosos de la Ciencia Política no le dieron el valor e interés que requiere, el transcurrir de los años ha permitido identificar cualidades comunes entre personajes influyentes en el desarrollo de la humanidad y la importancia de la personalización de los procesos políticos. Personajes del pensamiento político como Platón conciben la política como el arte de dirigir la comunidad como su razón moral de ser y, al líder, como el que está al servicio del pueblo y promulga leyes para el mayor bien común de sus ciudadanos. Nicolás Maquiavelo, sin embargo, lo definía en su obra "El Príncipe" como el conjunto de capacidades, habilidades y acciones orientadas a la adquisición y consolidación de poder.

Para hablar sobre la evolución del liderazgo en Venezuela, es necesario, mencionar el fenómeno del Caudillismo, cuyo origen nace, según (Vallenilla Lanz, 1991: 55); "Porque en la guerra de Independencia se perdió la organización social y ante tal anarquía... El gendarme necesario", es la encarnación misma del poder y mantiene la paz, el orden, la regularidad administrativa, el crédito interior y exterior, estos hombres, nacidos de la guerra y de la anarquía, son la única fuerza de conservación social en los pueblos que evolucionan hacia la consolidación de su individualidad nacional". Así mismo se debe caracterizar las distintas caracterizaciones que tiene el liderazgo político en Venezuela en las siguientes dimensiones: 


\section{Dimensiones del Liderazgo Político en Venezuela}

\subsection{Dimensión política}

En Venezuela, la época democrática se da a partir del bipartidismo Acción Democrática AD y del El Comité de Organización Política Electoral Independiente COPEI, que comenzó con el Pacto de Punto Fijo en el año 1958 que permitía la alternabilidad del poder entre los diferentes liderazgos que nacían dentro de las organizaciones políticas, a comienzos de los años 90 dicha participación se vio ampliada, al darse el proceso de descentralización y la elección por voto popular de cargos estatales y municipales, que dieron base al nacimiento de nuevos liderazgos.

Sin embargo, para el momento, el país vivía una crisis de partidos, debido a las acciones políticas de los períodos presidenciales de Carlos Andrés Pérez y Rafael Caldera que dio el fin al bipartidismo de la época y determina la debilidad de los partidos políticos, el nacimiento del liderazgo de Hugo Chávez que se alimentó del protagonismo del mismo en los eventos sociales y políticos de la época, desde su llegada al poder, en el país, el desarrollo de los liderazgos se da a partir de los eventos políticos del período, con nuevos liderazgos que permitió a pequeños líderes consagrarse como líderes nacionales, a partir de los hechos del referéndum revocatorio, elecciones presidenciales y de gobernaciones y alcaldías, se dieron liderazgos que aún son importantes para el país, a pesar de que mediante mecanismos constitucionales las posibilidades de los mismos cada vez se volvieron más minimizadas, así como con el fallecimiento del Presidente Hugo Chávez y la llegada al poder de Nicolás Maduro.

\subsection{Dimensión socio-cultural}

Así como el nacimiento del liderazgo del fallecido Hugo Chávez tuvo su origen en hechos de carácter social, a partir del año 1999 se da el nacimiento de muchos liderazgos a partir de hechos importantes a nivel social, como los hechos del año 2002- 2003 que fueron la suma de muchos factores sociales, económicos y políticos, más adelante hechos que causaron conmoción nacional, la caída de la calidad de vida y el empobrecimiento de la sociedad permitieron el nacimiento de muchos de nuestros líderes políticos de la actualidad, ya que representaron los intereses del pueblo y consiguieron de ese modo el apoyo que les permitió consolidarse como tal. 
Gustavo Adolfo Soto Vásquez, Zoribeth Carolina Lugo Vera y Jenileth Dairene Nava Medina

\subsection{Dimensión ético-moral}

Para ser un gran líder se necesitan valores que permitirán definir la calidad de su liderazgo. El líder como toda persona posee muchos defectos y virtudes que debe conocer. La ética y la moral son los valores principales que deben caracterizarlos, toman la ética como los principios que formaran luego su moral, que a su vez forman parte de una serie de principios, valores o normas que rigen su comportamiento. Ambos hacen referencia al comportamiento, normas, percepciones y el deber ser. Esto varía dependiendo de la sociedad o cultura que tengan los mismos.

\subsection{Dimensión jurídico-legal}

En Venezuela, se han realizado cambios constitucionales e institucionales que buscan siempre favorecer los intereses de los mandatarios, por lo que con la llegada de Hugo Chávez esta constante no fue una excepción, se creó un nuevo pacto social que entró en vigencia en el año 1999, para el líder, el interés más importante era la forma de mantenerse en el poder, alargando el periodo presidencial. A partir de ello, y de ciertos acontecimientos sociales históricos, en el año 2007 se llevó a cabo un Referéndum de Reforma Constitucional que, entre otros cambios, proponía en el Art. 230, alargar el periodo constitucional y además permitía la reelección indefinida para el Poder Ejecutivo, sin embargo, este proyecto fue rechazado. En el año 2009 se crea la propuesta de Enmienda Constitucional, que lograba la modificación de los Art. 160, 162, 174, 192, 230. El fin de dicha propuesta era la aprobación de la reelección de los cargos de elección popular, esto, ha sido un factor determinante para los liderazgos en Venezuela, debido a que ha logrado el cometido de la perpetración en el poder de los líderes de esta etapa, y han impedido que muchos de los nuevos líderes puedan lograr sus objetivos.

\subsection{Dimensión religiosa}

El liderazgo más emblemático e importante a nivel histórico, es el liderazgo religioso, en el caso de los cristianos, representado por Jesucristo, o también reconocido como el "Mesías". Con mesiánico, se hace referencia a Jesús que en su segunda venida llegará con el poder desde las nubes para juzgar y salvar de la muerte a los fieles. El liderazgo mesiánico ha tomado 
relevancia no solo en grupos religiosos, sino en grupos políticos y por ende en grupos sociales, es un tipo de liderazgo que ha ido tomando importancia sobre todo en los últimos años, un líder que llega al establecimiento de un nuevo orden, con su influencia sobre otras personas que les distingue de sus seguidores. En Venezuela, la viva representación de estas características fueron las del fallecido presidente Hugo Chávez, que revolucionó la forma en la que en Venezuela se conciben a los líderes, dificultando muchas veces el logro de los objetivos de otros. El liderazgo del mismo, marcó un antes y un después en las características de los liderazgos, se pretende a partir de ello, hacer un estudio de los liderazgos en el período mencionado.

\subsection{Dimensión ideológica}

El liderazgo político en Venezuela durante el periodo a abordar ha estado fuertemente influenciado por un proceso ideológico que empezó cuando Hugo Chávez llegó al poder el 1998. Desde la Asamblea Nacional Constituyente en el año 1999 el país empezó una serie de cambios institucionales impulsados desde la perspectiva ideológica de un líder. Sobre la base de una nueva propuesta ideológica, como lo es el Socialismo del Siglo XXI, y de sus rasgos personales el fallecido presidente Hugo Chávez construyó un liderazgo importante y fuerte que le permitió mantenerse en el poder hasta su muerte e incluso designar un sucesor, que lograría nuevamente ganar las elecciones frente a un líder opositor. A pesar de los intentos de la oposición de obtener el poder, no lo ha logrado. La coalición de partidos como han venido manejando su estrategia electoral no permite una propuesta ideológica única que aglutine votos más allá de los que puede aglutinar individualmente cada líder desde la proyección de su imagen y atributos personales.

\section{Liderazgo político}

Antes de hablar del liderazgo político, es necesario saber que es un líder, en palabras sencillas un líder según la Real Academia Española (2019), no es más que la "persona que dirige o conduce un partido político, un grupo social u otra colectividad", que tiene ciertas capacidades (delegar, tomar la iniciativa, convocar, incentivar, promover, gestionar, motivar y evaluar un plan o proyecto de forma eficaz y eficiente) para lograr las metas y objetivos del mismo. Ahora bien, luego de entender que es un líder y cuál es su rol, el liderazgo político ha sido estudiado desde tiempos 
remotos por intelectuales como Platón, Maquiavelo y Hobbes, conocida como la escuela del gran hombre, aunque no con la importancia que debidamente merecía, no fue hasta 1922 cuando Max Weber ${ }^{5}$ introdujo el término, y desde entonces se estudia como un tema específico. A pesar de que hay múltiples estudios sobre el liderazgo, estos solo han derivado en numerosas definiciones que pretenden aproximarse a la explicación más completa de este fenómeno político y social, y la mayoría de ellos coinciden en tres aspectos fundamentales sobre el fenómeno: 1. Es un proceso; 2. Está relacionado con la influencia y se ejerce dentro o sobre un grupo; y 3. Va encaminado a una meta (Northouse, 2001, citado por: Delgado, 2004). También podría decirse que desde las Ciencias Sociales se le ha empleado el término liderazgo básicamente de tres formas distintas. En primer lugar, entendiéndolo como un rasgo o cualidad atribuible a una persona. En segundo lugar, como atributo posicional o situacional y, en último término, en calidad de comportamiento. (Delgado, 2004). Esto ha dado paso a la formación de distintos enfoques para el estudio del liderazgo, como el liderazgo situacional, conductitas y de los rasgos de personalidad.

\section{Enfoque Situacional}

En palabras de Sánchez (2000) La Teoría del Liderazgo Situacional (TLS), fue creada por Hersey y Blanchard a finales de los años 6o, donde los autores hacen una recopilación sobre los estudios conocidos de tipo científico que hablan sobre la importancia del enfoque situacional respecto a la efectividad del liderazgo, definiéndolo como un proceso que permite alcanzar objetivos en ciertas situaciones, Herseyy Blanchard son conscientes de que: "Ningún estilo de liderazgo es óptimo en cualquier situación, sino que si los subordinados son diferentes deben ser tratados de un modo distinto. La efectividad del liderazgo depende de la interacción entre el líder, los subordinados y otras variables situacionales" (Sánchez, 2000: 3).

Dicho modelo, creado por los autores, y adaptado por Sánchez (2000) muestran que hay cuatro estilos que miden el nivel de control que ejerce en nuestro caso, el líder y los subordinados, denominados: Ordenar, Persuadir, Participar y Delegar. Este modelo incluye además dos dimensiones de conducta del líder, conocidos como conducta de tarea que es el nivel del líder de dividir las tareas o responsabilidades del grupo, es una explicación detallada del qué, cuándo, dónde y por qué y la conducta de relación, donde el líder escucha, facilita y respalda a los seguidores. 
El éxito, también depende del nivel de madurez de los subordinados, incluye, experiencia, motivación, competencia e interés de los mismos por realizar las tareas que se le asignan que se convierten en responsabilidades. Dicha madurez, puede ser clasificada como baja, donde el líder ordena, cuando la madurez moderada el deber del líder es Persuadir si es baja y cuando la madurez es alta el líder debería persuadirlos a Participar y cuando su madurez es alta, Delegar.

\section{Diagrama No. 1}

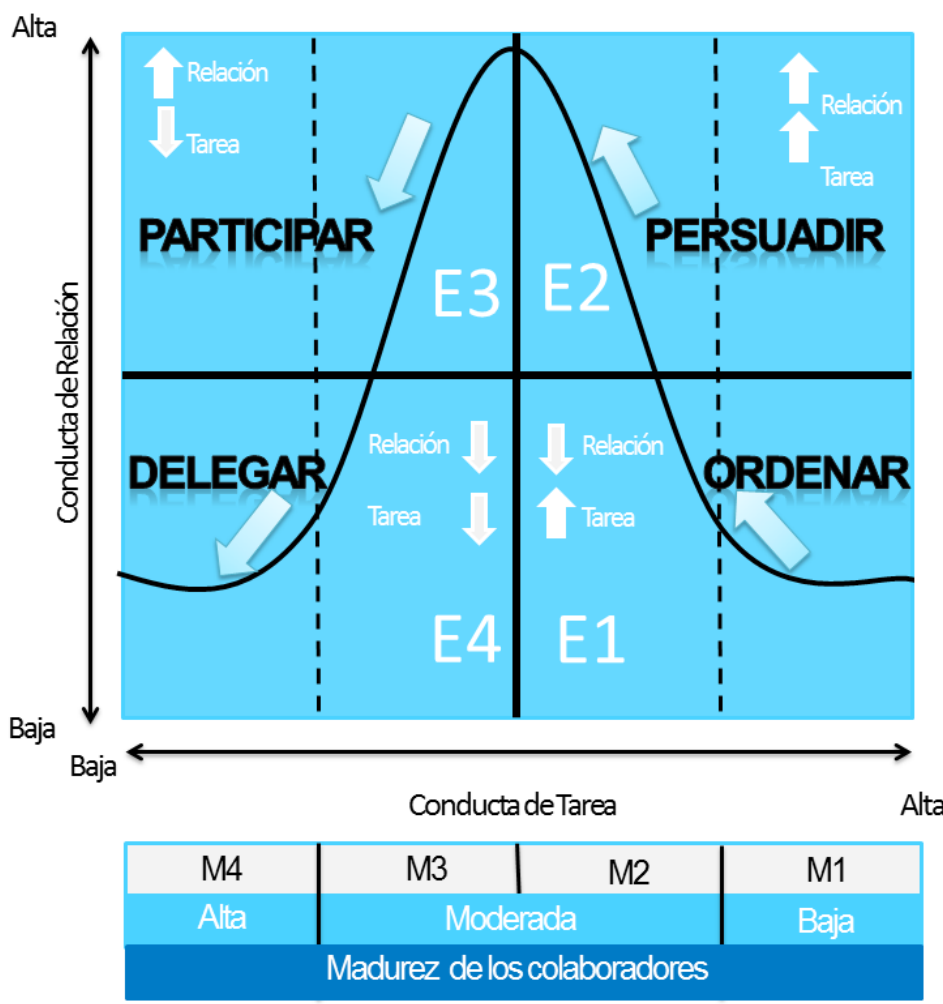

Figura 1. Fuente: (Sánchez, 200o) Teoría del liderazgo situacional en la Administración local: validez del modelo.

Sobre este enfoque de liderazgo podemos añadir, además:

$\mathrm{Al}$ enfoque que sostiene que las características de la situación del grupo en un momento dado (-condiciones socioeconómicas, estructuras organizacionales, patrones culturales, etcétera) Predetermina qué acciones son proclives a constituir a un individuo como líder y cuáles impedirán el surgimiento de otros referentes (Coronel, 2015: 43). 
Lo que revela que el liderazgo es al mismo tiempo un proceso objetivo y subjetivo que no solo depende de las capacidades del sujeto líder, sino además, de las condiciones socioeconómicas, políticas, culturales y organizacionales, entre otras, donde se desarrolla el liderazgo como relación abarcante y dinámica.

\subsection{Enfoque Conductual}

El liderazgo conductual, tuvo su auge en los años sesenta y se enfoca en hacer un análisis de las conductas de los líderes y la relación entre dichas conductas y la efectividad de su liderazgo. Esta teoría no se enfoca en conocer la figura del líder, sino los comportamientos específicos y han intentado encontrar las conductas más eficaces de los mismos. En palabras de Edinger (1964) el liderazgo conductual se define como:

Un fenómeno actitudinal, producto de las percepciones mutuas del líder y los seguidores, que se concreta en la atribución a la conducta del primero, de la habilidad para guiar y estructurar los modelos de conducta colectiva en la dirección deseada, de tal forma que las decisiones del líder sean implantadas por la acción del colectivo (Edinger, 1964, citado por: Márquez, 2012: 24).

De modo que, el liderazgo es en buena medida un fenómeno conductual que termina por configurar una estructura de personalidad con la habilidad para guiar las conductas colectivas, en función de los objetivos y propósitos que se desean alcanzar en términos de relacione de poder.

\subsection{Enfoque de los Rasgos Personales}

El enfoque más importante dentro del liderazgo, es el enfoque de los rasgos, que se basa en los atributos del individuo que ejerce el control sobre el comportamiento de otros. Para Ganga y Navarrete (2013) los rasgos a los cuales hace referencia este enfoque son características físicas, psicológicas y sociológicas, para los autores así como para varios estudiosos de este enfoque, estas características hacen más eficaces a los líderes pero no garantizan el éxito de los mismos. Gran parte de la importancia de este enfoque nace luego del aporte que daban los integrantes de la llamada Escuela del Gran Hombre:

La teoría del Gran Hombre tuvo un rol destacado y asumió que el líder es una persona poseedora de cualidades extraordinarias que son la fuente de su influencia, viéndose al liderazgo como un conjunto de cualidades innatas o adquiridas en una persona que podrían ser descubiertas, identificadas y medidas (Popper, 2000 citado por: Coronel, 2015: 42). 
En palabras de Coronel (2015), muchos de los estudios sobre este enfoque buscan sintetizar los más sobresalientes, cada uno de estos estudios le dan importancia a características tales como características físicas, otros analizaban cuestiones como inteligencia, determinación y originalidad.

La relación entre el éxito del liderazgo y las características personales del líder no es directa. No obstante, se trata de un factor relevante que no puede ser desestimado a priori. En cualquier caso, siempre conviene hacer un análisis complementario de la personalidad porque la posesión de ciertos rasgos característicos es muy apreciada en determinados momentos como, por ejemplo, a la hora de tomar decisiones (Post, 2004, citado por: Kalpokaite, 2014: 68).

Desde nuestro punto de vista sin embrago, todo indica que la relación liderazgo y las características personales del líder al menos en lo concerniente a su estructura de personalidad y a sus capacidades políticas si es más importante de los que Post supone. No obstante, todo depende del líder que se estudie en particular y su situación histórica concreta.

\section{Personalización política}

La personalización política es un fenómeno cuyos orígenes los autores han atribuido al siglo XX y que guardaría estrecha relación con el desarrollo de los medios de comunicación de masas, este fenómeno consiste en la concentración y acentuación de la atención en los rasgos personales y la imagen de los políticos y candidatos, más que sus mensajes y propuestas. La personalización de la política guarda estrecha relación con la "espectacularización" de la política de lo que se infiera que una lleva a la otra ineludiblemente. Además, asegura que este es un fenómeno que se manifiesta con mayor frecuencia en sistemas presidencialistas y sistemas electorales mayoritarios. Por otro lado, Laguna (2011) explica que la televisión como medio de comunicación social ha llevado a darle preponderancia al líder frente a las organizaciones (partidos) y frente a las propuestas programáticas o ideológicas de los partidos, conduciendo así a las sociedades a votar por los políticos y no por las políticas, recayendo de este modo el éxito electoral en el candidato.

De esta manera, la personalización política podría considerarse como una estrategia electoral y de comunicación política tiene como propósito resaltar las cualidades y atributos del líder, candidato o político con el fin de lograr votos por medio de simpatías personales, simplificando así el debate político. 


\section{Resultados}

Para la primera etapa abordada en la investigación que comprende desde el año 1999 hasta el año 2006, fueron seleccionados como informantes claves, los diputados: Williams Dávila y Juan Pablo Guanipa ${ }^{6}$, de acuerdo a los enfoques de estudio de liderazgo tomados para esta investigación el diputado Williams Dávila, a pesar de no reconocerse a sí mismo como líder de manera expresa, en forma tácita, reconoce cualidades en sí mismo, que lo posicionan como un líder de rasgos personales y hace mención a características coincidentes con el mismo. Para el diputado, el liderazgo se basa en atributos individuales que pueden tener un actor político como la ética, la lealtad y valores morales, así como también, menciona la importancia de la formación académica para la conquista de espacios de participación política.

\section{Diagrama No.2 (entrevista Dip. Williams Davila)}

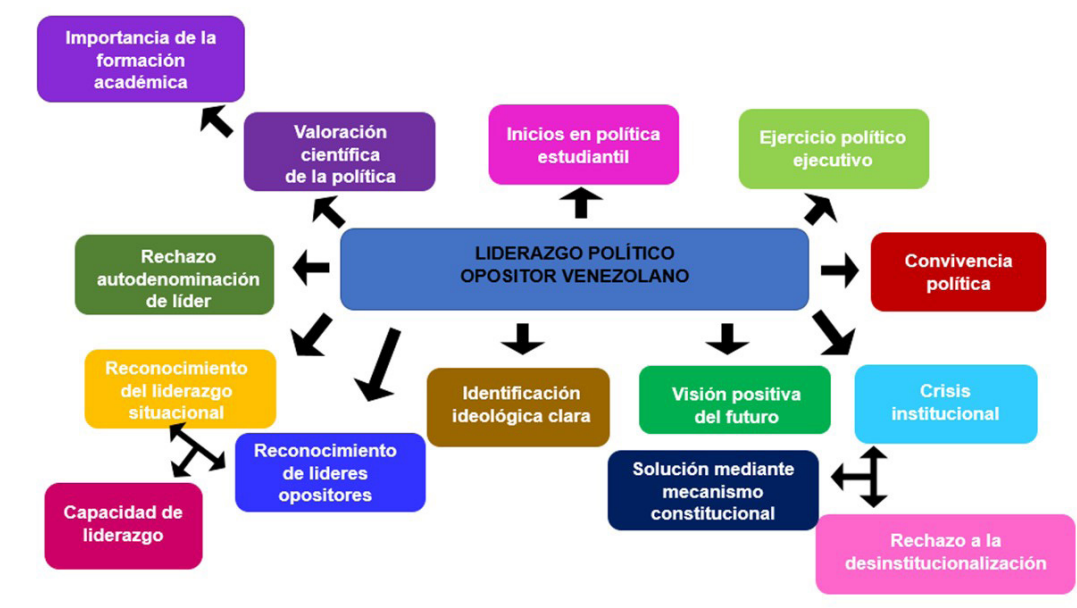

Lugo, Nava, Soto (2017) Evolución y características del liderazgo político opositor en el período 1999-2015.

Williams Dảvila, 66.

Así mismo, en el caso del diputado Juan Pablo Guanipa, a través de la entrevista se encontraron en él características del enfoque de liderazgo de los rasgos personales, resaltando la importancia de valores, como: solidaridad, honestidad y humildad, además presenta características del enfoque de

6 Reconocidos políticos venezolanos, el primero militante de Acción de democrática y el segundo de Primero justicia, ambos son opositores. 
liderazgo conductual, ya que menciona como ha sido su crecimiento y los cambios adoptados en su conducta para la consolidación de su liderazgo, también muestra características tales del enfoque de liderazgo situacional, ya que hace referencia a la importancia del trabajo en equipo y de la efectiva toma de decisiones delegadas en el mismo.

\section{Diagrama No. 3 (entrevista Dip. Juan Pablo Guanipa)}

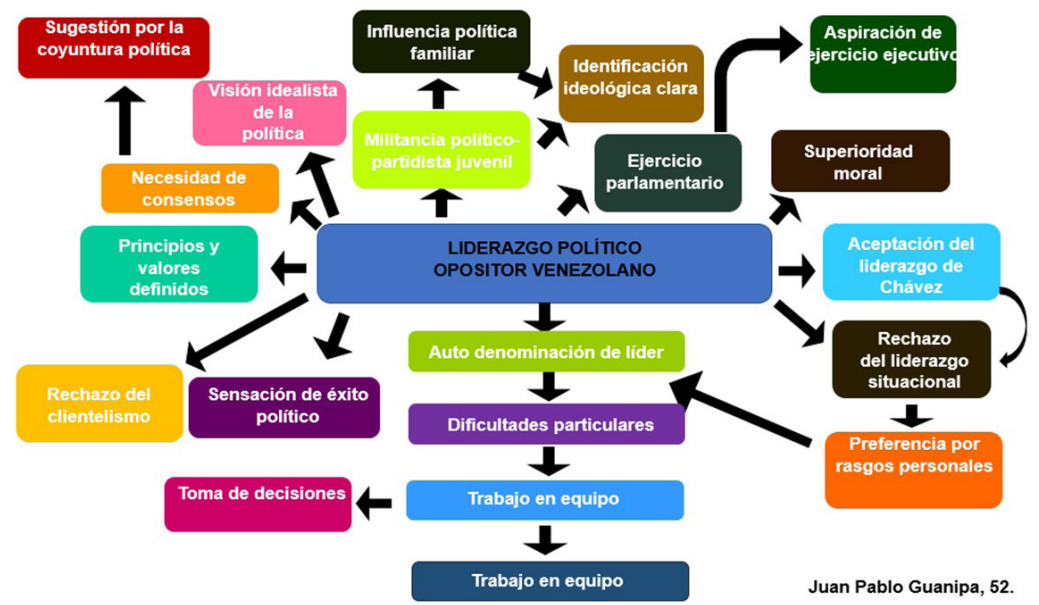

Lugo, Nava, Soto (2017) Evolución y características del liderazgo político opositor en el período 1999-2015.

Para la segunda etapa a abordar en la investigación que comprende desde el año 2007 hasta el año 2012, fueron seleccionados como informantes claves, los diputados, Stalin González y Juan Guaidó. En el caso, del diputado Stalin González, se pudo precisar que su estilo de liderazgo predominante es el estilo de liderazgo conductual, destacando características como la importancia en la conducción de grupos sociales y la articulación de los partidos políticos para que funcionen como medios para alcanzar espacios de participación política, además, como característica del enfoque de los rasgos personales hace mención a la importancia de la formación académica. También muestra características del enfoque de liderazgo situacional ya que hace mención de la importancia de la persuasión y conducción de los grupos sociales, la delegación de tareas y la importancia de mantener la armonía en el equipo. 


\section{Diagrama No.4 (entrevista Dip. Stalin González)}

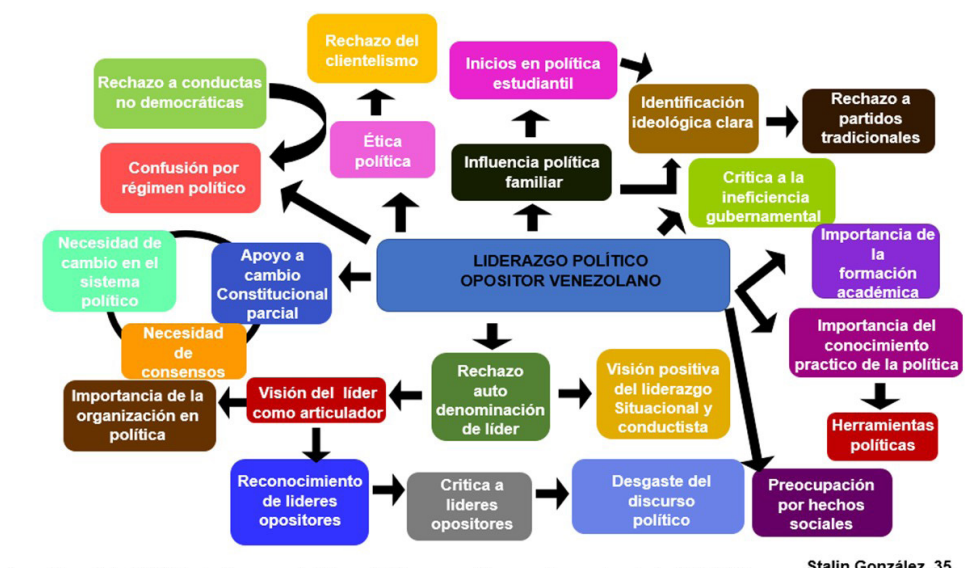

Lugo, Nava, Soto (2017) Evolución y características del liderazgo político opositor en el período 1999-2015.

Stalin González, 35

Por otro lado, el diputado Juan Guaidó, se caracteriza por el enfoque de liderazgo de los rasgos personales, haciendo referencia a las cualidades y atributos que debe poseer un líder, mencionando la nobleza, lealtad y sentido de justicia, así como el compromiso que asumen los mismos; además, posee características del enfoque de liderazgo conductual, ya que reconoce la importancia del surgimiento de nuevos líderes en coyunturas específicas.

\section{Diagrama No. 5 (entrevista Dip. Juan Guaido)}

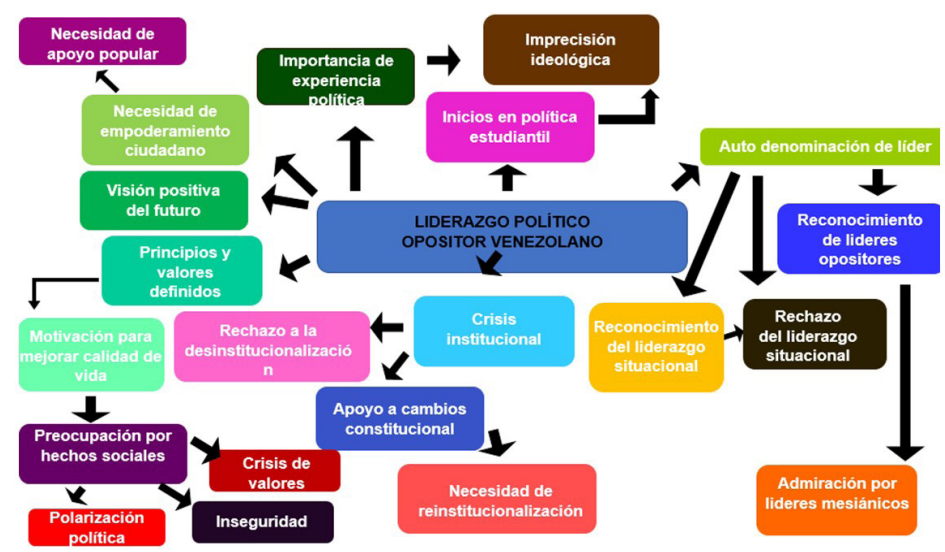


Para la etapa que comprende el año 2013 y el año 2015, fue posible definir que el diputado Simón Calzadilla, responde únicamente al enfoque de liderazgo de los rasgos personales, ya que hace mención a la capacidad comunicacional que debe tener un líder, perseverancia, honestidad, compromiso ético y humildad. Dentro de la entrevista, el diputado, no hizo mención a ninguna característica de los dos enfoques de liderazgos que se estudian en esta investigación.

\section{Diagrama No 6 (entrevista Dip. Simón Calzadilla)}

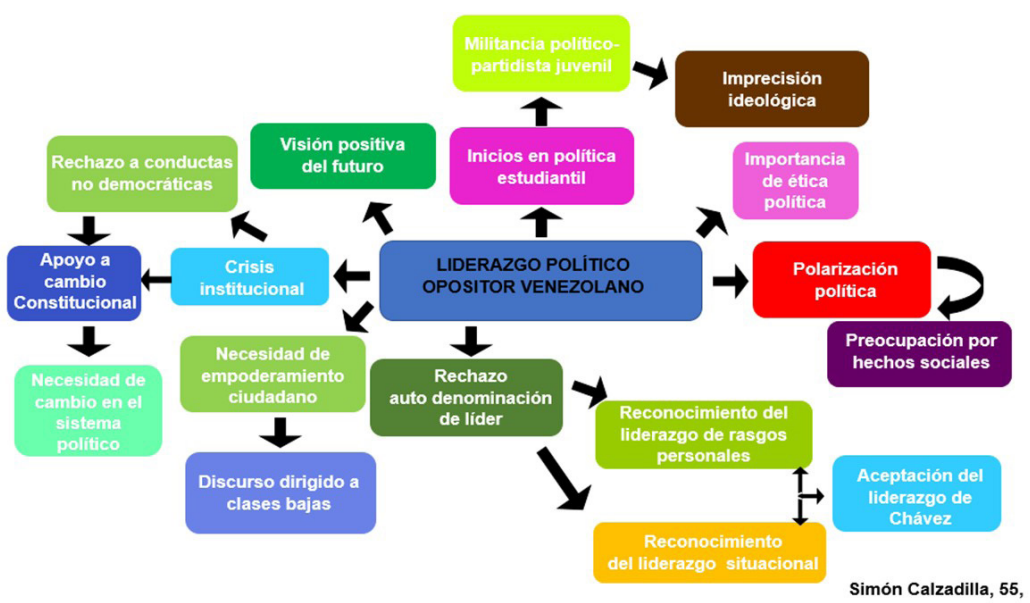

Lugo, Nava, Soto (2017) Evolución y características del liderazgo político opositor en el período 1999-2015.

$\mathrm{Y}$ en el caso, del diputado Juan Requesens se destaca su clara y firme caracterización del enfoque de los rasgos personales, enfatizando características como la humildad y la vocación de servicio. También hace mención a características del enfoque de liderazgo conductual, haciendo referencia a la constancia que deben tener los mismos y la construcción de un liderazgo que se va fortaleciendo con el tiempo. 


\section{Diagrama No. 7 (entrevista Dip. Juan Requenses)}

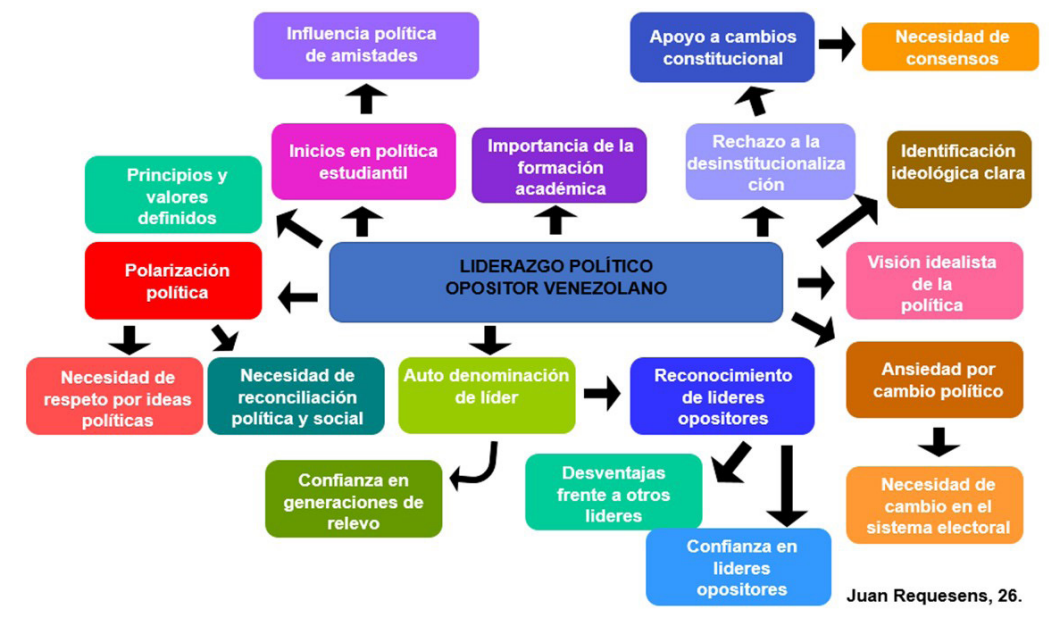

Lugo, Nava, Soto (2017) Evolución y características del liderazgo político opositor en el período 1999-2015.

Los informantes claves de la etapa que comprende el año 1999- 2006, han tenido una evolución política lenta, el diputado Williams Dávila ha tenido espacios de acción política ejecutiva como gobernador, bajo decreto del presidente Jaime Lusinchi en el año 1984 y nuevamente bajo elección popular para el periodo 1995-2000, y finalmente ocupa cargos políticos legislativos cuando es elegido diputado a la Asamblea Nacional, mientras que el diputado Juan Pablo Guanipa solo ha sido elegido popularmente para ocupar espacios de participación política legislativa y hasta el momento en que fue concedida la entrevista no había alcanzado espacios de participación política ejecutiva. La evolución de los líderes políticos de la segunda y tercera etapa de esta investigación ha sido más rápida, ya que han conseguido conquistar espacios de participación política en menor tiempo que los de los líderes políticos de la primera etapa.

Los entrevistados para la primera etapa de la investigación muestran una clara precisión ideológica y muestran concordancia entre su posición ideológica y el partido político al cual pertenecen. Los entrevistados para la segunda y tercera etapa de la investigación muestran imprecisión en su posición ideológica y muestran poca concordancia entre su posición ideológica y el partido político al cual pertenecen, los diputados de la primera etapa tienen mayor preparación académica, aunque tienen menor contacto y poco carisma hacia sus seguidores, y su trabajo político partidista es bajo. Los diputados de la segunda etapa, por el contrario, tienen mucho contacto y carisma hacia sus seguidores y su trabajo político partidista es 
mayor, sin embargo, tienen una formación académica menor. Mientras que los diputados de la tercera etapa de la investigación han encontrado el equilibrio entre su trabajo partidista, su carisma y su formación académica.

\section{Diagrama No.8 Liderazgo Político Opositor}

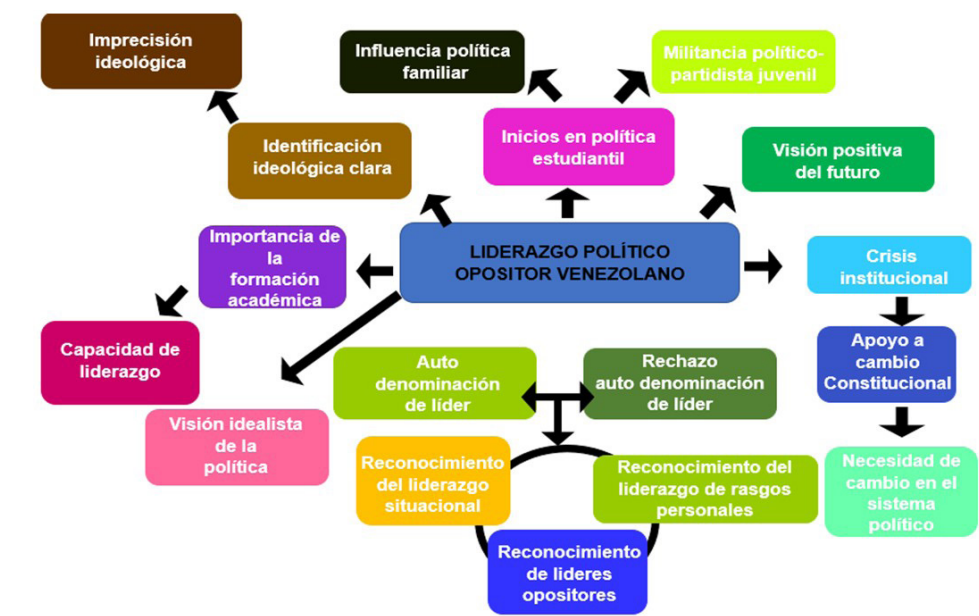

Lugo, Nava, Soto (2017) Evolución y características del liderazgo político opositor en el período 1999-2015.

Todos los informantes claves muestran poca coincidencia en su línea discursiva, con la excepción dela importancia política y social quele atribuyen al ex presidente Hugo Chávez. Los entrevistados con la excepción del diputado Juan Pablo Guanipa, crean su propio discurso y no siguen la línea discursiva del partido político al cual pertenecen todos los entrevistados, poseen características del enfoque de liderazgo de los rasgos personales, solo con la excepción del diputado Stalin González, cuyas características son tales del enfoque de liderazgo conductual. También los informantes claves, tuvieron inicios políticos desde espacios estudiantiles, con la excepción del diputado Juan Pablo Guanipa cuyos inicios políticos tuvieron su origen desde la influencia política familiar, enfatizando en su figura paterna y el diputado Juan Requesens que confiesa tener una influencia política desde sus amistades, sin embargo, su crecimiento también se desarrolló dentro de los espacios estudiantiles

A pesar de aceptar y reconocer la importancia de los liderazgos bajo el enfoque conductual, todos rechazan este enfoque, ya que afirman que no es la forma correcta de construir un liderazgo político sólido. Y respecto a su visión de país, los diputados de la primera etapa, tienen una visión 
idealista y les resulta muy importante la necesidad del rescate de las instituciones políticas. La visión de país para el diputado Stalin González es una visión realista y haciendo alusión a las necesidades del país menciona la importancia de la realización de consensos entre oposición y gobierno al momento en que fue concedida la entrevista, mientras que el diputado Juan Guaidó tiene una visión idealista y hace mención a la necesidad de rescatar las instituciones políticas del país y el rescate de la familia como la institución más importante de la sociedad. La visión de país para el diputado Juan Requesens es mayormente idealista, sin embargo, hace alusión a visiones realistas de respeto y pluralismo, mientras que el diputado Simón Calzadilla hace referencia a una visión realista del país, y dando importancia al verdadero empoderamiento ciudadano para lograr instituciones más sólidas.

\section{Conclusiones}

No se encontraron muestras significativas de evolución o cambios en el comportamiento de los líderes políticos, ni por sus diferencias de edad, ni por la época o coyuntura política en la que emergieron como líderes. Sin embargo, se encontraron diferencias a nivel discursivo que corresponden únicamente al criterio personalísimo de cada uno de los líderes, y no a las líneas de sus partidos.

Los líderes políticos opositores no han tenido gran trascendencia más allá de espacios legislativos por la dificultad de crear consensos en una coalición política, conformada por distintos partidos políticos con posturas ideológicas distantes que además actúan como partidos atrapa-todo, y esto no permiten la unificación de criterios conceptuales y criterios estratégicos para hacer frente y presentarse como alternativa ante una parcialidad política altamente cohesionada y con vocería única.

Todos los líderes presentan características de liderazgos situacionales, de rasgos personales y conductuales, sin embargo, se encontraron en cada uno de ellos más atributos coincidentes con el estilo del liderazgo de los rasgos personales. El liderazgo opositor venezolano ha personalizado la política reduciendo el debate político a figuras relevantes dentro de cada uno de los partidos y la influencia que desde sus atributos personales puedan tener sobre los ciudadanos, en lugar de orientar el debate en una nueva dirección, sobre la base de ideas y categorías claves. 


\section{Referencias Bibliográficas}

CORONEL, Alejandro Aníbal. 2015. Estilos de liderazgo político democrático: Argentinay España en perspectiva comparada. Universidad Complutense de Madrid. Madrid. Disponible en línea. En: eprints.ucm.es/34479/1/ T36738.pdf. Fecha de consulta:10/02/2017.

DELGADO, Santiago. 2004. "Sobre el concepto y estudio del liderazgo político" En: Revista de Psicología Política. Universidad de Granada. Disponible en línea. En: www.uv.es/garzon/psicologia\%2opolitica/N29-1.pdf. Fecha de consulta:10/02/2017.

GANGA, Francisco; NAVARRETE, Erwin. 2013. "Enfoques asociados al liderazgo eficaz para la organización” En: Revista Gaceta Laboral vol. 19. Universidad del Zulia. Disponible en línea. En: http://www.redalyc.org/ articulo.oa?id=33626721007. Fecha de consulta: 28/03/2018.

HUNTINGTON, Samuel. 1972. El orden político en las sociedades en cambio. Editorial Paidos. Buenos Aires, Argentina.

KALPOKAITE, Neringa. 2014. Características psicosociales del liderazgo político en los procesos de la transición hacia la democracia. Análisis comparado entre los líderes de España y Lituania. Universidad Complutense de Madrid. Madrid. Disponible en línea. En: eprints.ucm.es/28385/1/ T35735.pdf. Fecha de consulta: 28/10/2018.

LAGUNA, Antonio. 2011. "Liderazgo y comunicación: la personalización de la política” En: Revista Anàlisi. Universidad Autónoma de Barcelona. Disponible en línea. En: https://ruidera.uclm.es/xmlui/bitstream/ handle/10578/1786/fi_1322582592-131124831pb1.pdf. Fecha de consulta: $10 / 02 / 2018$.

MARQUEZ, Carmen. 2012. Calidad democrática y la neoconstitucionalización del liderazgo político: Un acercamiento al caso de Venezuela y Bolivia. Fundación de Estudios de Derecho Administrativo. Caracas, Venezuela.

REAL ACADEMIA ESPAÑOLA. 2019. Diccionario de la lengua española. Disponible en línea. En: https://dle.rae.es. Fecha de consulta: 10/06/2019.

SANCHEZ, Emilio. 200o. "Teoría del liderazgo situacional en la Administraciòn Local: validez del modelo" En: Revista Psicothema vol. 12. Universidad de Oviedo. Disponible en línea. En: http://www.redalyc.org/articulo. oa?id=72712316. Fecha de consulta: 27/09/2017. 
Gustavo Adolfo Soto Vásquez, Zoribeth Carolina Lugo Vera y Jenileth Dairene Nava Medina

180 Características y evolución del liderazgo político opositor venezolano en el periodo 1999-2015

VALLENILLA LANZ, Laureano. 1991. Cesarismo democrático y otros textos. Fundación biblioteca Ayacucho. Caracas, Venezuela.

VILLAROEL, G; LEDEZMA, N. 2007. "Carisma y política. El liderazgo de Hugo Chávez desde la perspectiva de sus partidarios” En: Revista Politeia Vol. 30. Universidad Central de Venezuela. Disponible en línea. En: http:// www.redalyc.org/articulo.oa?id=170018341001. Fecha de consulta: 11/02/2017.

WEBER, Max. 2007. La ciencia como profesión. La política como profesión. Austral Ciencias Humanas. Madrid, España. 

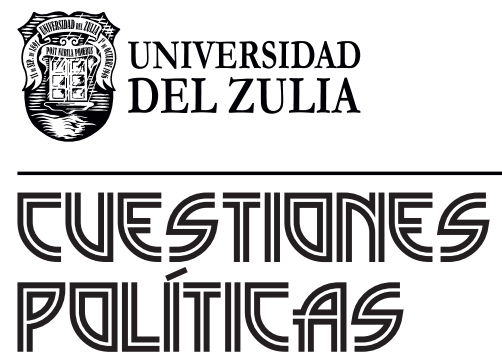

Vol. $37 \mathrm{~N}^{\circ} 64$

Esta revista fue editada en formato digital y publicada en junio de 2020, por el Fondo Editorial Serbiluz, Universidad del Zulia. Maracaibo-Venezuela 